\title{
Peningkatan Pemahaman Masyarakat Kelompok Nelayan Desa Pahlawan Tentang Konsep Dasar Perdagangan Internasional
}

\author{
Dewi Mahrani Rangkuty ${ }^{1 *}$, Sanusi Ghazali Pane ${ }^{2}$, Hartato Rianto ${ }^{3}$, Miftahul Jannah ${ }^{4}$ \\ ${ }^{1234}$ Fakultas Sosial Sains, Universitas Pembangunan Panca Budi \\ *email: dewimahrani@dosen.pancabudi.ac.id
}

\begin{abstract}
This community service activity aims to improve the understanding of the community of Pahlawan village fishermen as a service partner on the basic concept of international trade. The method of devotion is done by (1) observes; (2) counselling/socialization lectures; and (3) evaluation. The results of the devotion showed that the group of fishermen as participants/forums have shown enthusiasm in attendance, receiving information as an effort to add knowledge and insight from the method of counselling lectures/socialization of materials that have been conducted by the dedicated team. The team's recommendation for further community service activities after this stage is to perform the same methods with different themes such as differences in the number of fishermen's catches before and during the Covid-19 pandemic that can affect the export performance of fishery subsectors. To return to become additional information knowledge and insight in the community of the Pahlawan village fishermen group.
\end{abstract}

Keywords: Catches, Fisheries, Fishermen, Subsectors, Trade

\begin{abstract}
Abstrak
Kegiatan pengabdian kepada masyarakat ini bertujuan untuk meningkatkan pemahaman masyarakat kelompok nelayan desa Pahlawan sebagai mitra pengabdian tentang konsep dasar perdagangan internasional. Adapun metode pengabdian yang dilakukan yakni dengan (1) observasi; (2) ceramah penyuluhan/sosialisasi; dan (3) evaluasi. Hasil pengabdian menunjukkan bahwa kelompok nelayan sebagai pesertalforum telah menunjukkan antusiasme dalam kehadiran, menerima informasi sebagai upaya menambah pengetahuan dan wawasan dari metode ceramah penyuluhan/sosialisasi materi yang telah dilakukan oleh tim pengabdian. Rekomendasi tim untuk kegiatan pengabdian masyarakat selanjutnya setelah tahapan ini adalah agar dilakukan metode yang sama dengan tema yang berbeda seperti perbedaan jumlah hasil tangkap nelayan sebelum dan selama pandemi Covid-19 yang dapat mempengaruhi kinerja ekspor subsektor perikanan. Dengan tujuan agar kembali menjadi informasi tambahan pengetahuan dan wawasan pada masyarakat kelompok nelayan desa Pahlawan.
\end{abstract}

Kata Kunci: Hasil Tangkap, Nelayan, Perdagangan, Perikanan, Subsektor

\section{PENDAHULUAN}

Masyarakat Desa Pahlawan 89\% bekerja sebagai nelayan dan buruh laut [1] karena letak geografis di dataran rendah Kecamatan Tanjung Tiram Kabupaten Batu Bara Provinsi Sumatera Utara. Desa Pahlawan memiliki 1.452 kepala keluarga [2] dimana nelayan sebagai kepala rumah tangga dan wanita nelayan sebagai ibu rumah tangga memiliki peran sebagai penjaga dan penerus kehidupan [3]. Nelayan juga tidak lepas dari konsumsi rumah tangga dalam pemenuhan kebutuhan ekonomi.

Hasil tangkap nelayan adalah seluruh jenis hasil tangkapan oleh nelayan di laut dalam hitungan jam tertentu dengan menggunakan alat tangkap. Alat tangkap 
adalah alat yang dipergunakan nelayan untuk melakukan penangkapan. Jenis alat tangkap yang digunakan para nelayan yakni jaring insang, pancing tonda, pancing ulur, rawai dasar dan sero [4]. Alat tangkap kebanyakan yang digunakan oleh masyarakat kelompok nelayan desa Pahlawan adalah alat tangkap jaring angkat. Jenis alat tangkap yang digunakan nelayan menentukan tingkat produktivitas nelayan tersebut mengingat alat tangkap

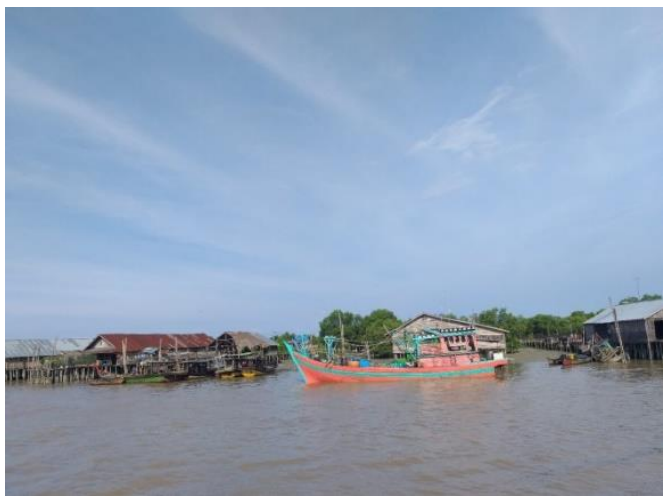

Gambar 1. Pelabuhan Tanjung Tiram Lokasi Sekitar Desa Pahlawan

Perikanan merupakan salah satu sub sektor yang berperan penting dalam pembangunan ekonomi. Pada kenyataannya, pembangunan nasional di Indonesia juga didukung oleh sub sektor perikanan. Akan tetapi pada kenyataannya, pelaksanaan pembangunan perikanan dalam negeri masih terdapat permasalahan yang cukup besar [7].

Komoditas perikanan hasil tangkap nelayan Indonesia telah menjadi komoditas ekspor terutama pada hasil tangkap udang dan lobster [8]. Sehingga komoditas ekspor udang dan lobster menjadi subsektor yang berkontribusi pada peningkatan jumlah devisa Indonesia. Kegiatan ekspor merupakan bagian dari perdagangan internasional [9] menjual barang ke luar negeri dengan tujuan memperoleh keuntungan. Keuntungan yang didapat akan menambah pendapatan negara melalui devisa. yang digunakan dapat mempengaruhi jenis-jenis hasil tangkap yang didapatkan para nelayan [5]. Hasil tangkap nelayan juga merupakan jumlah produksi oleh nelayan desa Pahlawan [6]. Hasil tangkap nelayan desa Pahlawan menjadi pemenuhan kebutuhan konsumsi masyarakat desa itu sendiri, masyarakat sekitar dan masyarakat luas sebagai pemenuhan kebutuhan masyarakat dalam provinsi.

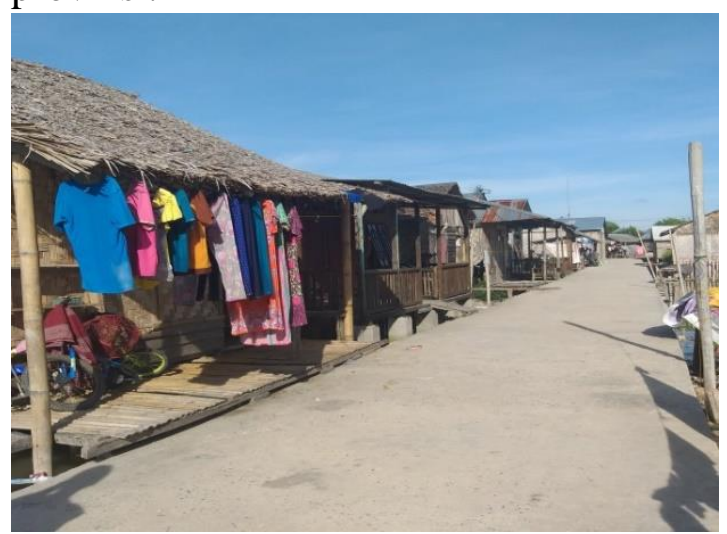

Gambar 2. Pemukiman Masyarakat Nelayan Desa Pahlawan

Hasil tangkap nelayan yang merupakan subsektor perikanan turut membantu perekonomian daerah dan nasional. Namun kehidupan para nelayan masih melekat stigma kemiskinan dan ketidaksejahteraan [3]. Ini tercermin dari masih terbatasnya pengetahuan, wawasan dan informasi para nelayan di daerah pesisir salah satunya seperti di desa Pahlawan. Keterbatasan ini yang menjadi motivasi bagi penulis dan tim dalam melaksanakan kegiatan pengabdian kepada masyarakat dalam upaya meningkatkan pemahaman masyarakat kelompok nelayan desa Pahlawan tentang konsep dasar perdagangan internasional ekspor sehingga dengan adanya kegiatan ini dapat menjadi wadah dan ruang diskusi yang membawa perubahan pada pengetahuan dasar dan wawasan kelompok nelayan tentang konsep hasil tangkap yang menjadi komoditas ekspor. 


\section{METODE PENGABDIAN}

Adapun metode yang dilakukan dalam pengabdian kepada masyarakat ini terdiri atas 3 (tiga) tahap yakni: (1) Obersvasi; (2) Penyuluhan/Sosialisasi; (3) Evaluasi. Observasi awal menuju desa Pahlawan sebagai lokasi pengabdian kepada masyarakat telah dilakukan pada tahun 2017 dengan berkoordinasi langsung kepada Kepala Desa Pahlawan Kecamatan Tanjung Tiram Kabupaten Batu Bara Provinsi Sumatera Utara sebagai mitra pengabdian kepada masyarakat.

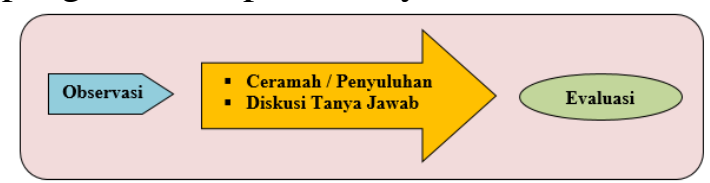

Gambar 3. Metode Pengabdian

Kegiatan penyuluhan juga telah berlangsung di tahun tersebut. Saya dan tim melakukan penyuluhan/sosialisasi dengan teknik ceramah sharing ilmu dengan menggunakan slide presentasi menyajikan materi dalam bentuk teks, gambar dan video, kemudian ditutup dengan diskusi tanya jawab bersama masyarakat kelompok nelayan desa Pahlawan sebagai upaya adanya feedback yang bertemakan konsep perdagangan internasional dengan judul peningkatan pemahaman masyarakat kelompok nelayan desa pahlawan tentang konsep dasar perdagangan internasional.

Tahap akhir dari metode pengabdian ini yaitu evaluasi. Hasil evaluasi saya dan tim dilakukan dengan melihat jumlah peserta/forum yang hadir dari undangan yang telah disebar dan melihat bagaimana antusiasme peserta/forum dalam ruang diskusi tanya jawab kepada saya dan tim sebagai narasumber dalam kegiatan ini.

\section{HASIL DAN PEMBAHASAN}

Kegiatan pengabdian masyarakat dilakukan di kantor Kepala Desa Pahlawan dengan mengundang masyarakat kelompok nelayan sebagai peserta/forum. Konsep dasar perdagangan internasional adalah sebagai tema dan mengangkat pembahasan pada hasil tangkap nelayan pesisir di pelosok negeri mempunyai nilai unggul sehingga menjadi komoditas ekspor yang mendatangkan devisa bagi negara.

\section{Hasil tangkap nelayan}

Indonesia yang merupakan negara kepulauan terbesar di dunia dengan \pm 17.508 pulau dan wilayah perairan menjadi zona ekonomi eksklusif. Sehingga dengan kondisi geografis demikian, Indonesia memiliki potensi pengembangan subsesktor perikanan hasil tangkap [8]. Komoditas yang menjadi unggul dari hasil tangkap nelayan adalah udang dan lobster. Dan penangkapan udang di perairan Indonesia cukup pesat mengingat udang menjadi komoditas yang memiliki nilai jual tinggi dibandingkan hasil tangkap lainnya [10].

Dalam pengabdian ini saya dan tim membahas jenis-jenis hasil tangkap nelayan yang dikenal oleh masyarakat yang biasanya dapat diakses di pasar. Jenis yang dimaksud seperti ikan, kerang, kepiting, cumi, udang, lobster dan lain sebagainya. Selain dijual di pasar, namun sebenarnya hasil tangkap para nelayan ada juga yang menjadi komoditas unggul yakni seperti udang dan lobster. Komoditas unggul dari hasil tangkap yang dimaksud adalah hasil tangkap nelayan yang mempunyai kualitas baik sehingga mempunyai nilai jual tinggi.

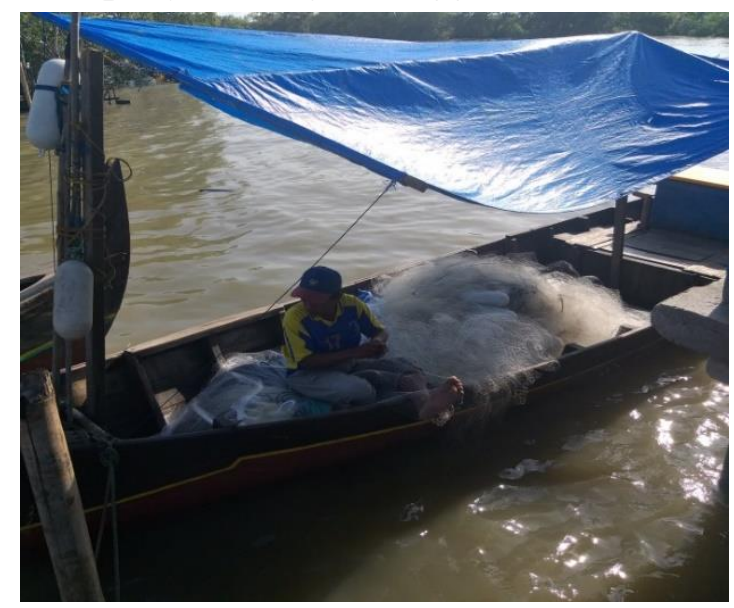

Gambar 4. Salah Satu Nelayan Desa Pahlawan 


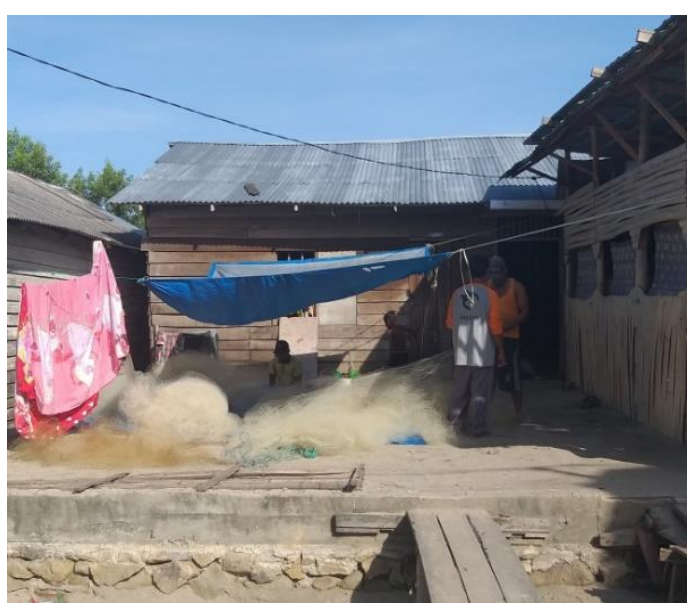

Gambar 5. Kelompok Nelayan dan Alat Tangkap Jaring Angkat

\section{Sosialisasi konsep perdagangan antara dalam negeri dan luar negeri}

Dalam kegiatan ini saya dan tim meberi penyuluhan menyampaikan konsep definisi dasar secara sederhana apa itu perdagangan dalam negeri dan perbedaannya dengan perdagangan luar negeri. Tim pengabdian dalam menyampaikan materi ceramah penyuluhan/sosialisasi dengan menggunakan bahasa yang sangat sederhana dan mudah dimengerti oleh kelompok nelayan sebagai peserta/forum. Pada kenyataannya, dengan menyampaikan melalui bahasa yang sederhana dan mudah dimengerti sehingga peserta/forum dapat dengan mudah paham dan mengerti materi perbedaan perdagangan antara dalam negeri dan luar negeri secara sempurna. Di samping juga dibarengi dengan penyampaian melalui gambar dan video.

\section{Subsektor perikanan}

Dalam perhitungan pendapatan regional dan nasional terdapat salah satu sektor pertanian dan terdiri dari salah satunya adalah subsektor perikanan. Subsektor memberi peluang ekonomi berdasarkan hasil tangkap nelayan dengan berbagai jenis sehingga dapat memenuhi kebutuhan di dalam negeri hingga ke luar negeri. Hasil tangkap nelayan subsektor perikanan ini bergantung pada alat tangkap yang digunakan [7]. Pada kenyataannya, udang dan lobster ternyata yang menunjukkan permintaan tinggi di pasar terutama pasar internasional karena kualitasnya sehingga menyebabkan nilai jual tinggi [11].

Dalam kegiatan ini saya dan tim memperkenalkan bahwa dari beberapa jenis hasil tangkap nelayan, udang dan lobster menjadi komoditas unggulan yang diekspor ke luar negeri. Atau dengan kata lain hasil tangkap nelayan udang dan lobster adalah yang paling banyak dijual ke luar negeri karena peminat yang banyak dari negara-negara mitra dagang Indonesia di pasar internasional. Udang dan lobster hasil tangkap nelayan Indonesia telah banyak dikonsumsi oleh negara-negara lain.

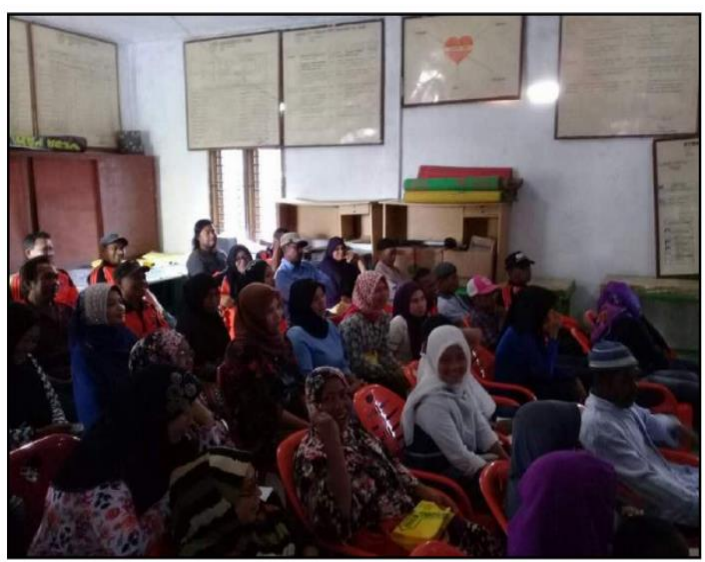

Gambar 6. Masyarakat Kelompok Nelayan Desa Pahlawan

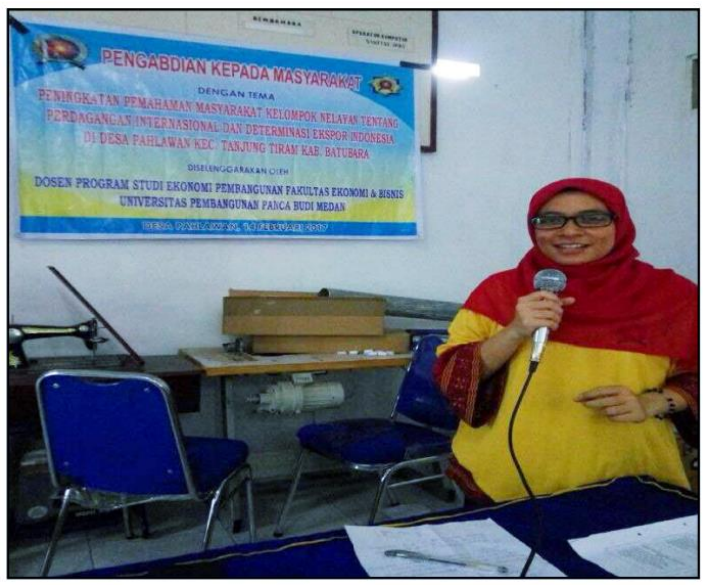

Gambar 7. Narasumber Saat Melakukan Metode Ceramah 


\section{Sosialisasi kenapa hasil tangkap nelayan menjadi komoditas ekspor}

Berdasarkan tahap ceramah materi yang telah dilakukan sebelumnya, dalam tahap ini saya dan tim berusaha mengajak pada ruang diskusi tanya jawab kepada peserta/forum tentang alasan kenapa hasil tangkap nelayan menjadi komoditas ekspor. Pada awalnya kami sebagai tim pengabdian memberi kesempatan kepada peserta/forum yang ingin memberi tanggapan dengan berani dan bebas berpendapat atas dasar informasi materi yang telah disampaikan pada tahap sebelumnya. Lalu tim menyampaikan argumen sebagai jawaban bahwa hasil tangkap nelayan menjadi komoditas ekspor dikarenakan kualitas (bibit) yang bagus dan mempunyai nilai jual tinggi, komoditas dimaksud adalah udang dan lobster seperti yang telah disampaikan sebelumnya.

\section{Hasil evaluasi}

Pada tahap ini adalah tahap akhir dari pengabdian ini, hasil evaluasi menunjukkan bahwa masyarakat kelompok nelayan sebagai peserta/forum pengabdian telah hadir sebanyak $\pm 90 \%$ dari jumlah undangan yang telah disebar dan diinformasikan melalui kepala desa yang terdiri dari kelompok nelayan, para nelayan sebagai bapak rumah tangga dan wanita nelayan sebagai ibu rumah tangga nelayan. Kegiatan ceramah penyuluhan/sosialisasi materi yang telah dilakukan terlihat antusiasme peserta/forum dalam menerima dan menampung informasi untuk menambah pengetahuan dan wawasan. Selain itu, suasana dalam berdiskusi dan tanya jawab memperlihatkan hasil yang maksimal ditunjukkan dengan keaktifan beberapa peserta/forum dalam mengajukan pertanyaan yang silih berganti. Kegiatan pengabdian seperti ini memang menjadi kebutuhan oleh masyarakat kelompok nelayan desa pahlawan.

\section{SIMPULAN}

Kegiatan pengabdian kepada masyarakat ini bermitra pada masyarakat kelompok nelayan desa Pahlawan telah mendapat respon positif. Kelompok nelayan sebagai peserta/forum telah menunjukkan antusiasme dalam kehadiran, menerima informasi sebagai upaya menambah pengetahuan dan wawasan dari metode ceramah penyuluhan/sosialisasi materi yang telah dilakukan oleh tim pengabdian. Sebagai harapan dari tim bahwa kegiatan pengabdian ini dapat membawa perubahan pada pengetahuan, wawasan dan informasi kelompok nelayan desa pahlawan tentang konsep dasar perdagangan internasional yang membawa pada hasil tangkap nelayan menjadi komoditas ekspor sehingga berkontribusi pada devisa negara.

Rekomendasi tim untuk kegiatan pengabdian masyarakat selanjutnya setelah tahapan ini adalah agar dilakukan metode yang sama dengan tema yang berbeda seperti perbedaan jumlah hasil tangkap nelayan sebelum dan selama pandemi Covid-19 yang dapat mempengaruhi kinerja ekspor subsektor perikanan. Dengan tujuan agar kembali menjadi informasi tambahan pengetahuan dan wawasan pada masyarakat kelompok nelayan desa Pahlawan.

\section{UCAPAN TERIMAKASIH}

Ucapan terima kasih penulis kepada Kepala Desa Pahlawan Kecamatan Tanjung Tiram Kabupaten Batu Bara dan seluruh masyarakat kelompok nelayan sebagai mitra, kepada Ketua Program Studi dan Mahasiswa Ekonomi Pembangunan Universitas Pembangunan Panca Budi yang telah mendukung dan membantu dalam kegiatan pengabdian kepada msyarakat ini sehingga dapat berjalan dengan lancar. 


\section{DAFTAR PUSTAKA}

[1] B. Efendi, “Analisis Pola Kunsumsi Masyarakat Nelayan Di Desa Pahlawan Kecamatan Tanjung Tiram Kabupaten Batu Bara," Abdi Ilmu, vol. 10, no. 2, pp. 1844-1850, 2017, [Online]. Available: http://jurnal.pancabudi.ac.id/index. php/abdiilmu/article/view/43/26.

[2] DJPT, Petunjuk Teknis Bantuan Sarana Penangkapan Ikan DJPT Tahun Anggaran 2017, 1st ed. Jakarta: KKP DJPT, 2017.

[3] A. Novalina and Rusiadi, "CONFirmatory Factor Analysis Terhadap Kemandirian Ekonomi Wanita Pesisir Berbasis Kesejahteraan Keluarga Nelayan Desa Pahlawan Kecamatan Tanjung Tiram," Jepa, vol. 3, no. 1, pp. 6574, 2018.

[4] A. Ahmad, L. Anadi, and R. D. Siang, "Identifikasi Hasil Tangkapan Dan Keuntungan Nelayan Tangkap Di Kelurahan Langara Laut Kecamatan Wawonii Barat Kabupaten Konawe Kepulauan," J. Sos. Ekon. Perikan., vol. 3, no. 1, pp. 47-61, 2018.

[5] I. Limbong, E. S. Wiyono, and R. Yusfiandayani, "Faktor-Faktor Yang Mempengaruhi Hasil Produksi Unit Penangkapan Pukat Cincin Di Ppn Sibolga, Sumatera Utara," Albacore, vol. 1, no. 1, pp. 89-97, 2017.

[6] D. M. Rangkuty, "Analisis Penilaian Penerapan Bantuan Alat Tangkap Pada Hasil Tangkap Nelayan Pesisir Desa Pahlawan Kecamatan Tanjung Tiram Kabupaten Batu Bara," Ekonomikawan, vol. 18, no. 1, pp. 59-68, 2018, [Online]. Available: http://jurnal.umsu.ac.id/index.php/e kawan/article/view/2153/pdf_95.

[7] K. Kusdiantoro, A. Fahrudin, S. H. Wisudo, and B. Juanda, "Kinerja Pembangunan Perikanan Tangkap
Di Indonesia," Bul. Ilm. Mar. Sos. Ekon. Kelaut. Dan Perikan., vol. 5, no. 2, Dec. 2019, doi: 10.15578/marina.v5i2.8053.

[8] A. P. D. Nasution, "Analisis Perkembangan Ekspor Subsektor Perikanan di Indonesia," Universitas Muhammadiyah Sumatera Utara, 2017.

[9] N. . Mankiw, E. Quah, and P. Wilson, "Pengantar Ekonomi Makro: Principle of Economics An Asian Edition," in Volume 2, Jakarta: Salemba Empat, 2012.

[10] Nofrizal, F. Ramdhani, and R. Jhonnerie, "NILai Finansial Dan Potensi Konflik Perikanan Udang Mantis Di Kuala Tungkal, Jambi," J. Ilmu Dan Teknol. Kelaut. Trop., Vol. 12, No. 1, Pp. 25-36, Apr. 2020 , doi: 10.29244/jitkt.v12i1.27223.

[11] H. Boesono, S. Anggoro, and A. N. Bambang, "Laju Tangkap dan Analisis Usaha Penangkapan Lobster (Panulirus Sp) Dengan Jaring Lobster (Gillnet Monofilament) di Perairan Kabupaten Kebumen," J. SAINTEK Perikan., vol. 7, no. 1, pp. 77-87, 2011, doi: 10.14710/ijfst.7.1.77-87. 